\title{
Sanctions and Taxes
}

\author{
Dulat Altynkhanov \\ Colliers International
}

\author{
Leon Taylor \\ KIMEP University
}

Are sanctions the most efficient means for convincing a nation to stop threatening security? We incorporate sanctions in a Robert Kohn trade model, likening security threats to global pollutants. Results suggest that Pigouvian taxes may contain the threats more efficiently than sanctions can. Econometric models of North Korea imply that comprehensive sanctions might reduce the number of arms tests. On the back of an envelope, we estimate that an income fall equivalent to about $7 \%$ of 2014 GDP might have eliminated all testing in 2015, controlling for the head of regime. But the result is not robust across all models.

\section{INTRODUCTION}

Foreign policy concerning such issues as the nuclear weapons of aggressive nations, like Iran and North Korea, may be fraught with uncertainty and potential error partly because it is not based on a rigorous model. This paper takes a step toward a model of sanctions and related tools that characterizes their Pareto efficiency or the lack thereof. When, for example, might we prefer taxes to sanctions?

To set the stage, we present an econometric model to suggest the conditions under which comprehensive sanctions may achieve their goal by reducing income per capita in a nation like North Korea. Despite the empirical possibility of success, sanctions may have perverse consequences: Applying sanctions to nondefense industries may induce labor and capital to move to the defense sector, which may stiffen opposition to cuts in testing. We use a Robert Kohn model to explore the conditions under which Pigouvian taxes may improve upon sanctions that limit trade. In principle, when security threats resemble global pollutants, Pigouvian taxes may deter them at a lower resource cost than sanctions do. We extend the sanctions model to the cases of international labor mobility, security threats that are impure public bads, military action after failed sanctions, and intrastate conflicts. The paper concludes with reflections on when a tax may be more appropriate than a sanction.

\section{ECONOMETRIC RESULTS}

Is success likely for sanctions that increase with the severity of the security threat? One might try to answer the question with a narrative case study; but this approach might not control for factors aside from the sanctions that may affect the severity of the threat. So we use econometrics to estimate, for North 
Korea, the impact of national income on the security threat, controlling for the military's share of gross domestic product (GDP) and for the type of political regime. This approach roots in a Heckscher-Ohlin model of two industries in which a nation produces security threats when its relative labor-capital ratio favors the production of arms (Samuelson 1948, 1949; Krugman, Obstfeld, \& Melitz, 2012). Sanctions curtailing the other industry may drive inputs into the arms industry, defeating the purpose of the sanctions. This reasoning suggests a positive relationship between the military's share of the economy and the production of security threats.

Table 1 presents an Ordinary Least Squares (OLS) model of North Korea in which missile and nuclear tests proxy for threats to international security. The model uses the first differences of two variables: the share of gross domestic product devoted to military spending (DME_GDP); and the number of arms tests (DTESTS). The advantage of differencing is that the differenced time series are stationary, unlike the levels of the two variables. KIM is a dummy variable for the years in which Kim Jong Un has been in power (that is, for 2011 up through the last year in the dataset, 2015). We estimated robust standard errors of the coefficient estimates to correct for serial correlation. And we used a lag of the military share of GDP to avoid the possibility that the number of arms tests might have affected the concurrent military share. The period studied begins in 1992, and the time series are annual.

Controlling for the military share of GDP, the Kim regime might account for two more tests per year when compared to the previous year than did the regimes of his father and grandfather. This estimate is statistically significant at the 10\% level of significance. (Since it is well-known that Kim Jong Un is determined to develop a nuclear state, we apply a one-tailed test to the KIM coefficient.) The impact of military spending on tests carries the wrong sign and is statistically insignificant. But the interactive term of the military share of GDP and the Kim dummy is positive and significant at the $1 \%$ level. When the military variable rises by $1 \%$, the number of annual tests that would be undertaken by Kim's regime, rather than by the previous ones, increases by 3.6 tests when compared to the prior year (Table 1). (The first difference of the military share of GDP is measured as a fraction, so a one-unit increase is a $100 \%$ increase in the share of GDP.)

This is broadly consistent with a Heckscher-Ohlin prediction that increasing the relative economic power of the military could raise the number of tests. Perhaps a stronger military legitimizes Kim's regime. On the other hand, under Kim Jong Il and Kim Il Sung, the military share of GDP did not relate to the number of tests with statistical significance. One might infer that if sanctions affect most heavily the nondefense sector, driving resources into the defense sector, then perverse consequences-increases in testing-may be stronger under Kim than under his predecessors. 


\section{TABLE 1 \\ IMPACT OF MILITARY SPENDING ON ARMS TESTS}

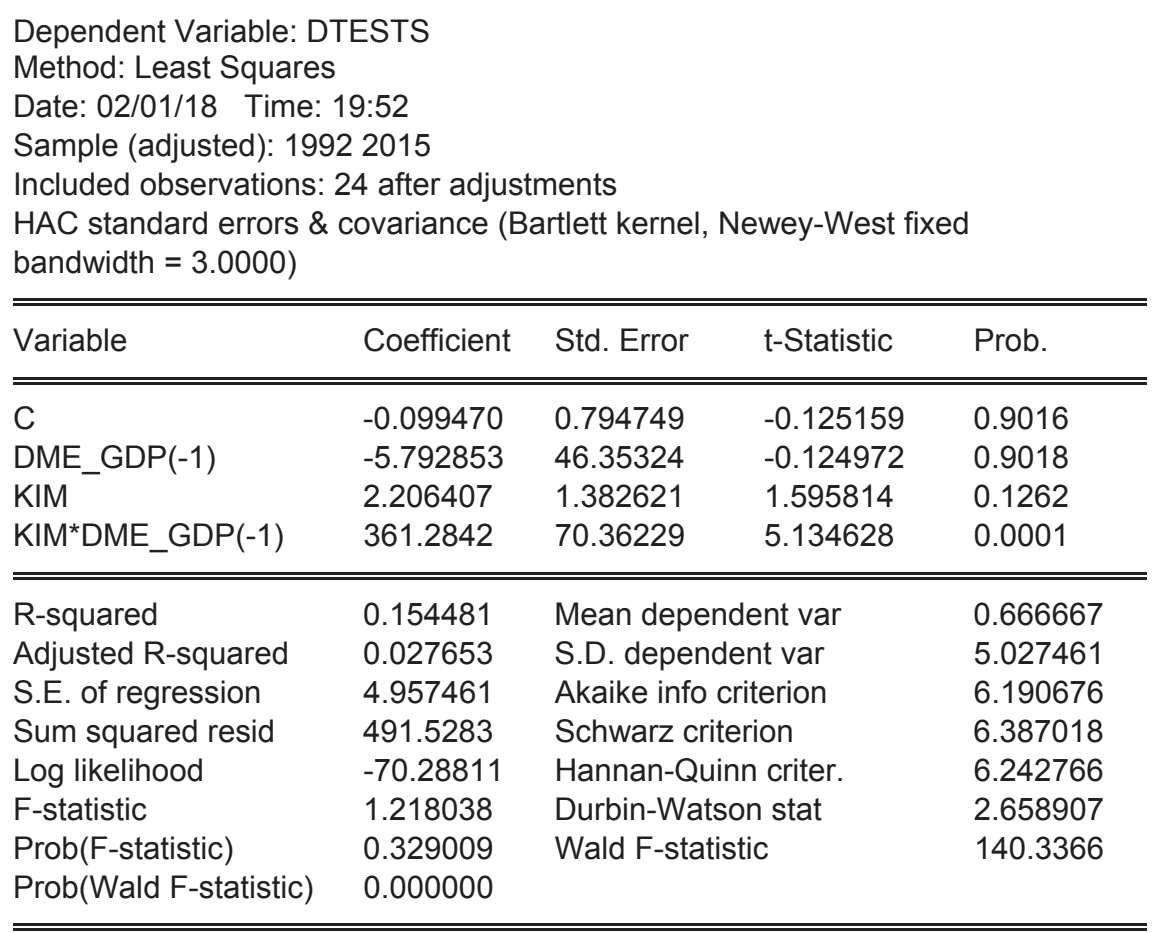

What kind of sanctions is more likely to curtail arms testing-sanctions targeted on Kim's acquaintances and aides, or sanctions on the national economy? To answer this question, we estimated models that included real GDP as an independent variable (Tables 2 and 3). We use the first difference of GDP to correct for nonstationarity, and we lag the variable since testing might otherwise affect concurrent GDP by inducing sanctions. We deploy Newey-West robust standard errors again to correct for serial correlation. Results indicate that with Kim in power, a unit decrease in the first difference of GDP might decrease the number of annual tests in the first difference by about 3.1 (Table 3). The interactive term again is statistically significant. In Table 2, KIM is significant at the $10 \%$ level of significance in a onetailed test-suggesting again that Kim Jong Un was more prone to arms tests than were his father and grandfather. The lag of the first-difference GDP as a standalone variable in Table 2 is not significant; but the power of the test may be low-there are only 19 degrees of freedom. In general, the dataset is small, and the statistical significance of GDP and the military share of GDP is not robust over all specifications.

In summary, we do not rule out the possibility that general economic sanctions might curtail arms tests. This conclusion may be at variance with the political conventional wisdom: "Politically...it is argued in unison that sanctions are ineffective in coercing the Kim Jong Un regime to abandon its nuclear weapons program" (Kwon, 2016, p. 140). But according to the Table 3 model in this paper, under Kim Jong Un's regime, a fall in the first difference of GDP of .22 of a unit may eliminate the mean first difference of the number of annual tests, which is .67. In other words, holding constant GDP in the prior year, annual testing may be stabilized by a reduction in current GDP equivalent to about $.3 \%$ of 2015 GDP. Eliminating all testing in 2015 would have required a reduction in GDP in 2014 of roughly $7 \%$.

Here are details of the calculation. By Table 3, a fall in DGDP of .218 of a unit would reduce DTESTS by .67 , which is the mean annual difference in tests. To arrive at this figure, note that the coefficient of the interactive term is 3.081. So the impact on DTESTS of a fall in DGDP of .218 is $.218 * 3.081$, or .67. Now, GDP in 2014 was 84.17. So the relative reduction in GDP needed to reduce DTESTS by .67 is $.218 / 84.17$, which is roughly .003; the required change in GDP is .3\%, holding prior 
GDP constant. Eliminating all 18 tests in 2015 would require a fall in 2014 GDP of roughly (18/.67)*.218 $=5.86$, again holding prior GDP constant. That is, we already have that a fall in DGDP of 218 reduces DTESTS by .67. So the number of .218-sized reductions in DGDP required to eliminate 18 tests is 18/.67. Multiplying this fraction by .218 gives us the required reduction in DGDP, which is 5.86 . This is roughly 7\% of 2014 GDP. These calculations are rudimentary and should be interpreted as merely indicative.

\section{IMPACT OF GDP ON ARMS TESTS}

\begin{tabular}{|c|c|c|c|c|}
\hline \multicolumn{5}{|c|}{$\begin{array}{l}\text { Dependent Variable: DTESTS } \\
\text { Method: Least Squares } \\
\text { Date: } 02 / 01 / 18 \text { Time: } 18: 26 \\
\text { Sample (adjusted): } 19922015 \\
\text { Included observations: } 24 \text { after adjustments } \\
\text { HAC standard errors \& covariance (Bartlett kernel, Newey-West fixed } \\
\quad \text { bandwidth }=3.0000)\end{array}$} \\
\hline Variable & Coefficient & Std. Error & t-Statistic & Prob. \\
\hline C & 0.257751 & 0.717891 & 0.359040 & 0.7235 \\
\hline $\operatorname{DGDP}(-1)$ & 0.550407 & 0.557440 & 0.987384 & 0.3359 \\
\hline DME_GDP(-1) & 32.76192 & 68.81079 & 0.476116 & 0.6394 \\
\hline$\overline{\mathrm{KIM}}$ & 1.376928 & 0.946355 & 1.454981 & 0.1620 \\
\hline DGDP $(-1)^{\star} \mathrm{KIM}$ & 2.424393 & 0.856271 & 2.831337 & 0.0107 \\
\hline R-squared & 0.171554 & \multicolumn{2}{|c|}{ Mean dependent var } & 0.666667 \\
\hline Adjusted R-squared & -0.002855 & \multicolumn{2}{|c|}{ S.D. dependent var } & 5.027461 \\
\hline S.E. of regression & 5.034633 & \multicolumn{2}{|c|}{ Akaike info criterion } & 6.253610 \\
\hline Sum squared resid & 481.6030 & \multicolumn{2}{|c|}{ Schwarz criterion } & 6.499038 \\
\hline Log likelihood & -70.04332 & \multicolumn{2}{|c|}{ Hannan-Quinn criter. } & 6.318722 \\
\hline F-statistic & 0.983630 & \multicolumn{2}{|c|}{ Durbin-Watson stat } & 2.761782 \\
\hline Prob(F-statistic) & 0.439972 & \multirow{2}{*}{\multicolumn{2}{|c|}{ Wald F-statistic }} & 5.665312 \\
\hline Prob(Wald F-statistic) & 0.003555 & & & \\
\hline
\end{tabular}

100 Journal of Leadership, Accountability and Ethics Vol. 16(1) 2019 


\section{TABLE 3 \\ A SIMPLE MODEL OF GDP AND ARMS TESTS}

\begin{tabular}{|c|c|c|c|c|}
\hline \multicolumn{4}{|c|}{$\begin{array}{l}\text { Dependent Variable: DTESTS } \\
\text { Method: Least Squares } \\
\text { Date: } 05 / 05 / 18 \text { Time: } 20: 23 \\
\text { Sample (adjusted): } 19922015 \\
\text { Included observations: } 24 \text { after adjustments } \\
\text { HAC standard errors \& covariance (Bartlett kernel, Newey-West fixed } \\
\quad \text { bandwidth }=3.0000)\end{array}$} & \multirow[b]{2}{*}{ Prob. } \\
\hline Variable & Coefficient & Std. Error & t-Statistic & \\
\hline $\mathrm{C}$ & -0.105263 & 0.743626 & -0.141554 & 0.8888 \\
\hline DGDP $(-1)^{*} \mathrm{KIM}$ & 3.080733 & 0.669226 & 4.603430 & 0.0002 \\
\hline KIM & 1.812457 & 0.944886 & 1.918176 & 0.0688 \\
\hline R-squared & 0.116372 & \multicolumn{2}{|c|}{ Mean dependent var } & 0.666667 \\
\hline Adjusted R-squared & 0.032217 & \multicolumn{2}{|c|}{ S.D. dependent var } & 5.027461 \\
\hline S.E. of regression & 4.945812 & \multicolumn{2}{|c|}{ Akaike info criterion } & 6.151428 \\
\hline Sum squared resid & 513.6821 & \multicolumn{2}{|c|}{ Schwarz criterion } & 6.298685 \\
\hline Log likelihood & -70.81713 & \multicolumn{2}{|c|}{ Hannan-Quinn criter. } & 6.190495 \\
\hline F-statistic & 1.382835 & \multicolumn{2}{|c|}{ Durbin-Watson stat } & 2.842849 \\
\hline Prob(F-statistic) & 0.272789 & \multirow{2}{*}{\multicolumn{2}{|c|}{ Wald F-statistic }} & 10.92484 \\
\hline Prob(Wald F-statistic) & 0.000560 & & & \\
\hline
\end{tabular}

The OLS models suggest that a Heckscher-Ohlin analysis is plausible but incomplete. R-squared is only about .12 to .17 .

Also, two econometric problems appear. One is that the smallness of the sample may have reduced the probability of rejecting a false null hypothesis (that is, the power of the test). The sample is hard to enlarge because of the lack of statistics about North Korea. In Table 1, the military share of GDP may be statistically insignificant either because it does not affect the population coefficient-despite the Heckscher-Ohlin prediction-or because of a lack of observations. The second problem is that an omitted variable may have biased some coefficient estimates regardless of sample size. We rely on the HeckscherOhlin specification to help us avoid this inconsistency, but the serial correlation in some models implies that an important variable may have been omitted.

\section{A GENERAL-EQUILIBRIUM ANALYSIS}

Samuelson $(1948,1949)$ showed that trade in goods can substitute for trade in their inputs. If Uzbekistan cannot send migrants to the farms of Russia, it can export labor-intensive cotton instead. Generally, if migration faces obstacles, there may be pressure to trade commodities. Producing more of certain commodities may generate external effects such as those due to pollution. Security threats may act like global pollutants: Their production may impose costs on the world that the domestic producer does not face and so does not take into account. Indeed, the producer may treat the external cost as a benefit to himself, because it extends his foreign influence. In that spirit, we draw upon Robert E. Kohn's (2002) model of environmental goods in international trade. The framework of the model below is Kohn's.

Kohn uses the Heckscher-Ohlin-Samuelson model to simulate the impact of environmental restrictions on a country that exports goods that generated pollution in their production. He assumes that production of a labor-intensive good X, in which a developing country ("South") has a comparative advantage, creates global pollution. Restrictions on the South would raise wages in the North for workers that produce $\mathrm{X}$, nurturing an alliance between Northern labor and environmentalists. Charging a 
Pigouvian tax on pollution would lead to Pareto efficiency. The potential Pareto improvement could enable the North to pay the South to induce it to consider global damages due to pollution.

We turn now to our application of the Kohn model. Denote as $N$ a nation that trades with the rest of the world, denoted as $G$. $N$ imports a labor-intensive good $X$ and exports a capital-intensive good $Y$. As an example of $Y$, North Korea and Iran might export "nuclear knowledge and heavy weapons and military equipment" (Charron, 2011).

Both nations produce both goods with labor and capital; production techniques are influenced by an information set $I$ that is larger for free trade than for a state-directed economy. The production functions are

$X\left(L_{x}, K_{x} ; I\right)$,

$Y\left(L_{y}, K_{y} ; I\right)$.

For each production function, the first derivatives with respect to $K$ or $L$ are positive and the second derivatives negative. For simplicity, we assume that cross partials are zero.

Since migration often figures in controversies over sanctions, we will let labor migrate between $N$ and $G$ although capital is specific to its location. The sum of labor endowments in $N$ and $G$ constrain total labor used, while capital in the given area is constrained by its endowment there:

$L_{0}^{n}+L_{0}^{g} \geq L_{x}^{n}+L_{y}^{n}+L_{x}^{g}+L_{y}^{g}$,

$K_{0}^{i} \geq K_{x}^{i}+K_{y}^{i}, i=n, \mathrm{~g}$

$Y$ has a by-product, threats to national security, measured as $e$. For example, $Y$ may denote military production and $e$ may be measured by the number of missile tests. Or, in Liberia in the early 2000s, one might have measured $e$ by the number of armed people not countenanced by the government.

We consider the utility functions of a representative of $N$ and of a representative of $G$ :

$U^{N}\left(x^{n}, y^{n}, e\right)$

$U^{G}\left(x^{g}, y^{g}, a e\right)$

In each utility function, the first two arguments have positive first derivatives and negative second derivatives. The third argument has a negative first derivative and a positive second derivative. The parameter $a$ permits the utility impact of $e$ to differ between the two countries.

Production of $Y$ in both countries, which might not use the same technology, generates security threats. Using a Kohn condition:

$e=E^{n}\left(Y^{n}\right)+E^{g}\left(Y^{g}\right)$

When $a=1$, the security threat is nonrivalrous and nonexcludable in areas $N$ and $G$. But in reality, a threat may be more potent in one area than in the other. Consider the 1935 invasion of Ethiopia (Abyssinia) by Italy. Some costs of the invasion fell entirely on the Ethiopians, such as the loss of population, capital, and freedom. But some other costs were global. For example, the success of the adventure may have raised the perception in other countries that they too could invade somewhere with profit.

To analyze such possibilities, write the threat as $a e$ in $G$, where $a$ is a parameter that equals 1 when the threat is a pure public bad but varies from 1 for other degrees of publicness. In our Italian example, $a$ may have exceeded 1 for the Ethiopians 
Although both countries produce $Y$, only $N$ exports it, since its inputs are capital-intensive. ( $G$ exports $X$, since its inputs are labor-intensive.) To counter security threats, $G$ may impose sanctions on exports of $Y$ from $N$ and on imports of $X$ into $N$. The sanctions are $\alpha_{\mathrm{e}}$ and $\alpha_{\mathrm{i}}$, which are between 0 and 1 for negative sanctions and are negative for positive sanctions. This paper will focus on negative sanctions. For example, if $G$ refuses to buy $20 \%$ of $N$ 's exports of $Y$, then $\alpha_{e}=.2$. In the model, the sanctions are increasing functions of $e$ : The more severe the security threat, the greater the sanctions imposed. A practical example may be the United Nations sanctions on North Korea.

The degree of sanctions also depends on $G$ 's ability to impose them on $N$. This ability relates directly to $G$ 's real income relative to $N$ 's. Denote this relative income as $Z^{g}$, a function of inputs and information sets $\left(L^{g}{ }_{0}, K^{g}{ }_{0}, I^{g}, L^{n}{ }_{0}, K^{n}{ }_{0}\right.$ and $\left.I^{n}\right)$. Thus $\alpha_{\mathrm{e}}$ and $\alpha_{\mathrm{i}}$ are positive functions of $e$ and $Z^{g}$.

The superscript $T$ denotes traded goods. The consumption functions for $N$ are

$x^{n}=X^{n}+\left(1-\propto_{i}\right) X^{T}$

$y^{n}=Y^{n}-\left(1-\propto_{e}\right) Y^{T}$ $\alpha_{\mathrm{e}} Y^{T}$.

Note that $N$ must consume the part of its exports that sanctions prevent it from selling. This amount is The consumption functions for $G$ are similar:

$x^{g}=X^{g}-\left(1-\propto_{i}\right) X^{T}$

$y^{g}=Y^{g}+\left(1-\propto_{e}\right) Y^{T}$.

$G$ imposes sanctions on $N$ with the intent of lowering the utility of an $N$ citizen to $U^{n}{ }_{0}$ - the point where he demands that his government reduce $e$. The citizen might be a representative of the population, but Allen and Lektzian (2012, p. 132) find in statistical studies that "democracies are generally less likely to be targeted by sanctions." The citizen might instead be a representative of an interest group critical to the government's survival, such as military leaders in Manuel Noriega's Panama in the late 1980s or in North Korea today (Kirshner, 1997).

In any case, we assume that the sanctioners want to lower the citizen's utility level, to $U_{0}^{n}$ if necessary. Thus

$U^{n}\left(x^{n}, y^{n}, e\right) \geq U_{0}^{n}$

This condition might apply to comprehensive sanctions. For targeted sanctions, the utility function might belong to the targeted political leader or to a representative of the group that backs him. In general, the condition seems consistent with Article 41 of the United Nations Charter- "the application of measures short of force that involve a deprivation of some sort," writes Charron (2011).

One might interpret this weak inequality as a measure of the target's resolve to resist the sanctions. For example, Kwon (2016, p. 154) writes that "the average North Korean's pain threshold [is] quite high." This implies a large utility differential in the inequality above. On the other hand, Lankov (2009, pp. 97-8) suggests that no utility differential for a representative citizen would induce concessions by Kim, because his grip on power does not depend on satisfying citizens. "The main victims of financial sanctions would be ordinary North Koreans, whose suffering has not hurt the regime historically. Even after three to five percent of the population starved to death in the late 1990s, there were no signs of political unrest.... When it comes to dealing with North Korea, in other words, the United States and its allies have no efficient methods of coercion at their disposal."

In some cases, $U^{n}{ }_{0}$ might fall below the subsistence level. For example, in the early $2000 \mathrm{~s}$, the Security Council initially balked at applying sanctions to the Democratic Republic of Congo because people were already suffering from civil war (Charron, 2011). 
The Lagrangian problem is

$$
\begin{aligned}
& \max L=U^{g}\left(x^{g}, y^{g}, a e\right)+\mu\left[X^{n}\left(L_{x}^{n}, K_{x}^{n}\right)+\left(1-\alpha_{i}[a e]\right) X^{T}-x^{n}\right]+v\left[Y^{n}\left(L_{y}^{g n}, K_{y}^{n}\right)-\left(1-{ }^{g} \alpha_{e}[a e]\right) Y^{T}\right. \\
& \left.-y_{n}\right]+\alpha\left[E^{n}\left[Y^{n}\left(L_{y}^{n}, K_{y}^{n}\right)\right]+E^{g}\left[Y^{g}\left(L_{y}^{g}, K_{y}^{g}\right)\right]-e\right]+\beta\left[L_{0}^{n}+L_{0}-L_{x}^{n}-L_{y}^{n}-L_{x}-L_{y}^{g}\right]+\gamma\left[K_{0}^{n}-K_{x}^{n}\right. \\
& \left.-K_{y}^{n}\right]+\delta\left[X^{g}\left(L_{x}, K_{x}^{g}\right)-\left(1-\alpha_{i}[a e]\right) X^{T}-x^{g}\right]+\eta\left[Y^{g}\left(L_{y}^{g}, K_{y}^{g}\right)+\left(1-\alpha_{e}[a e]\right) Y^{T}-\right. \\
& \left.y^{g}\right]+\tau\left[K_{0}^{g}-K_{x}^{g}-K_{y}^{g}\right]+\beta_{1}\left[U^{n}\left(x^{n}, y^{n}, e\right)-U_{0}^{n}\right] .
\end{aligned}
$$

The last constraint in Equation 13 ensures that we consider only situations in which $G$ may impose sanctions. Aside from the Lagrangian multipliers, the choice variables are $x^{n}, y^{n}, e, x^{g}, y^{g}, L_{x}^{n}, K_{x}^{n}, L_{y}^{n}, K^{n}{ }_{y}$, $X^{T}, Y^{T}, L_{x,}^{g}, L^{g}{ }_{y}, K_{x}^{g}$ and $K_{y}^{g}$.

Now suppose that producing $Y$ incurs no security threat at the margin, or that the threat is trivial. That is, suppose that $\frac{d E}{d Y^{n}}=0$ or $\alpha=0$. Then the optimality conditions would lead us to

$\frac{d U^{n}}{d x^{n}} \frac{d X^{n}}{d L_{x}^{n}}=\frac{d U^{n}}{d y^{n}} \frac{d Y^{n}}{d L_{y}^{n}}$.

It would be optimal for $N$ to allocate labor between the industries for $X$ and $Y$ so that it has the same marginal utility in either industry.

If the security threat is meaningful at the margin, then either $\frac{d E}{d Y^{n}} \neq 0$ or $\alpha \neq 0$ or both. We obtain the optimality condition

$$
\frac{\frac{d X}{d L_{x}^{n}}}{\frac{d y}{d L_{y}^{n}}}=\frac{v}{\mu}+\frac{\alpha \frac{d E}{d Y^{n}}}{\mu} .
$$

On the right-hand side of Equation 15, the first term represents the marginal product of labor with respect to $X$ in $N$, relative to the marginal product with respect to $Y$, when the security threat is not meaningful. Thus the second term on the right-hand side is the change in the relative marginal product with respect to $X$ that arises from the security threat. The greater the threat, the greater the optimal movement of labor from $Y$ to $X$.

Suppose that the marginal product of $Y$ in producing the security threat is the same in either $N$ or $G$. That is,

$$
\frac{d E}{d Y^{n}}=\frac{d E}{d Y^{g}}
$$

Then one new condition for optimality is

$$
\frac{d Y^{g}}{d L_{y}^{g}}=\frac{d Y^{n}}{d L_{y}^{n}}
$$

If the production of $Y$ has the same marginal impact in $G$ or $N$ on the security threat, then allocate labor between the two areas so that it has the same marginal impact on $Y$, since labor is mobile.

But suppose instead that the marginal impact of $Y$ on the security threat is larger in $N$ than in $G$ :

$\frac{d E}{d Y^{n}}>\frac{d E}{d Y^{g}}$

Then reallocate Y-labor from $N$ to $G$. 
As for the security threat $e$, Pareto efficiency requires that

$\frac{d U^{n}}{d e}=\frac{\propto}{\beta_{1}}-\frac{a}{\beta_{1}} \frac{d U^{g}}{d(a e)}$.

That is, producers of $Y$ should account for the marginal disutility of the security threat in both countries. (The Lagrangian multiplier $\alpha$ is non-positive.)

If producers of $Y$ in $N$ ignore the cost of the threat to $G$,

$\frac{d U^{n}}{d e}=\frac{\propto}{\beta_{1}}$

which implies an inefficiently high level of the security threat in the world.

Sanctions can address this problem, but another solution may be to penalize $N$ for producing another unit of $e$ by an amount reflecting $G$ 's marginal disutility. The Pigouvian tax is

$\operatorname{Tax}=-\frac{a}{\beta_{1}} \frac{d U^{g}}{d(a e)}$.

If $N$ values the additional unit of $e$-represented by, say, a missile test-by more than the cost that it imposes on $G$, then it will pay the tax and proceed. Otherwise, it will forego the missile test. In either case, the tax induces a decision that may increase social welfare.

In contrast, the sanctions aim to reduce the utility of the $N$ representative to level $U^{n}{ }_{0}$. It is not clear that this reduction in utility will be more than offset by the gain, particularly to the $G$ representative, of decreasing the security threat. There is no necessary relationship between the benefits that the sanctions procure and the costs that they impose. Hufbauer, Schott, Elliott, \& Oegg (2009, p. 108) note the occasional "recommendation that the sender country should seek to maximize the ratio of costs inflicted to costs incurred." This policy does not obviously enhance global efficiency.

\section{Violence After Sanctions}

Aggrieved nations often prefer sanctions to armies. In 1919, US President Woodrow Wilson observed that "boycott is what is substituted for war" (Hoffman 1967, p. 144). But when sanctions don't work, nations sometimes resort to military measures. For example, the Security Council authorized violence against North Korea in 1950, Southern Rhodesia in 1968, and against Iraq in 1991 after its comprehensive sanctions failed to persuade the country to withdraw troops from Kuwait (Charron, 2011). In 1999, the failure of sanctions in the former Yugoslavia was followed by NATO bombing runs on Serbs. From their econometric studies, Allen and Lektzian (2012) conclude that military conflicts and sanctions correlate positively. In interstate conflicts, often sanctions "are a prelude to force," writes Charron (2011). What principles might characterize violence following sanctions?

To analyze the question, we assume that those imposing sanctions cut off all trade with the offender and target its labor and capital that produce arms. For instance, the Security Council mandated stopping all imports and exports for Southern Rhodesia. In our notation, $G$ 's trade sanctions are complete: $\alpha_{i}=\alpha_{e}=$ 1. In addition, $G$ imposes sanctions on labor and capital that produce $Y$ for $N-\alpha_{L}$ and $\alpha_{K}$. For example, if $\alpha_{K}=.2$, then $G$ would destroy $20 \%$ of $N$ 's capital for producing $Y$. If $G$ demands unconditional surrender, then $\alpha_{L}=\alpha_{K}=1$. As before, the sanctions may be increasing functions of the security threat $e$. The model may also apply to nonviolent sanctions that have such extreme health effects as to resemble a "medieval siege" (Allen \& Lektzian, 2012, p. 122). Finally, we assume that labor is no longer mobile between the two areas. 
The optimization problem becomes

$$
\begin{aligned}
& \max L=U^{g}\left(x^{g}, y^{g}, e\right)+\mu\left[X^{n}\left(L_{x}^{n}, K_{x}^{n}\right)-x^{n}\right]+v\left[Y^{n 0}+Y^{n}\left(\left[1-\propto_{L}(e)\right] L_{y}^{n},\left[1-\propto_{K}(e)\right] K_{y}^{n}\right)-\right. \\
& \left.y^{n}\right]+\alpha\left[E^{0}+E^{n}\left[Y^{n}\left(\left[1-\propto_{L}(e)\right] L_{y}^{n},\left[1-\propto_{K}(e)\right] K_{y}^{n}\right)\right]+E^{g}\left[Y^{g}\left(L_{y}^{g}, K_{y}^{g}\right)\right]-e\right]+\beta\left[L_{0}^{n}-L_{x}^{n}-\right. \\
& \left.\left[1-\propto_{L}(e)\right] L_{y}^{n}\right]+\gamma\left[K_{0}^{n}-K_{x}^{n}-\left[1-\propto_{K}(e)\right] K_{y}^{n}\right]+\delta\left[X^{g}\left(L_{x}^{g}, K_{x}^{g}\right)-x^{g}\right]+\eta\left[Y^{g}\left(L_{y}^{g}, K_{y}^{g}\right)-y^{g}\right]+ \\
& \sigma\left[L_{0}^{g}-L_{x}^{g}-L_{y}^{g}\right]+\tau\left[K_{0}^{g}-K_{x}^{g}-K_{y}^{g}\right]+\beta_{1}\left[U^{n}\left(x^{n}, y^{n}, e\right)-U_{0}^{n}\right]
\end{aligned}
$$

For simplicity, we have assumed that $a=1$ - that is, the security threat is a pure public bad. Also, for convenience, we will use this notation:

$L_{Y}^{n *}=\left(1-\propto_{L}[e]\right) L_{Y}^{n}$

and

$K_{Y}^{n *}=\left(1-\propto_{K}[e]\right) K_{Y}^{n}$

Manipulations of first-order conditions yield

$\beta_{1} \frac{d U^{n}}{d e}+\frac{d U^{g}}{d e}=\alpha+\left(v+\alpha \frac{d E^{n}}{d Y^{n}}\right)\left[\frac{d Y^{n}}{d L_{Y}^{n *}} \frac{d \alpha_{L}}{d e} L_{Y}^{n}+\frac{d Y^{n}}{d K_{Y}^{n *}} \frac{d \alpha_{K}}{d e} K_{Y}^{n}\right]-\beta \frac{d \alpha_{L}}{d e} L_{Y}^{n}-\gamma \frac{d \alpha_{K}}{d e} K_{Y}^{n}$

If the violent measures $\alpha_{L}$ and $\alpha_{K}$ do not depend on the security threat $e$, then Equation 25 collapses to

$\beta_{1} \frac{d U^{n}}{d e}+\frac{d U^{g}}{d e}=\alpha$

In Equation 26, the left-hand side represents the marginal disutility to $G$ of the security threat, which has two parts. The direct effect is captured by the last term on the left-hand side. The first term reflects an indirect effect, which requires a word of explanation. By the envelope theorem, $-\beta_{1}=d U^{g} / d U^{n}{ }_{0}$. An increase in $e$ lowers $U^{n}$ and thus makes it easier for $G$ to reduce this utility to $U^{n}{ }_{0}$, which is the point of the violence. The sum of the direct and indirect effects on $G$ of the marginal security threat optimally equals the marginal disutility to $G$ of the background threat $E_{0}$, which is given by the right-hand side of Equation 26.

But when violence increases with $e$, Equation 25 obtains. On the right-hand side, the second term can be interpreted as the marginal value to $G$ of using violence to reduce $N$ 's defense output. In that term, the first expression, $v$, denotes the marginal disutility to $G$ of $N$ 's defense. In the second expression of the term, $\alpha$ denotes the marginal disutility to $G$ of the security threat, followed by a derivative expressing the rise in the threat to $G$ that is due to a marginal increase in $N$ 's defense output. Adding the two expressions in that second term on the right-hand side (which appears in parentheses) gives us the marginal cost to $G$ of $Y^{n}$ : the direct effect, then the indirect effect. Next, the brackets contain a measure of each of the two inputs into $Y^{n}$ that is lost to violence at the margin, weighted by the input's marginal product in generating $Y^{n}$. For a rough example, consider that in 1994, the Security Council heard complaints that its area-wide arms embargo crippled Bosnia and Herzegovina in their efforts to defend themselves (Charron, 2011).

The last two terms on the right-hand side of Equation 25 represent the value of $N$ 's marginal inputs lost to violence, having controlled for their defense services, in the optimal solution. For example, labor could have provided services to the community. Each of the two inputs is weighted by its marginal value (or cost) to $G$.

In general, the right-hand side of Equation 25 (setting aside the first term) expresses the shadow price to $G$ of $Y^{n}$ times the inputs into $Y^{n}$ that are lost to $G$ 's violence; minus the direct shadow prices to $G$ of the inputs $L^{n}$ and $K^{n}$ times the amounts of those inputs that are lost to $G$ 's violence. Consequently, the right- 
hand side expresses the marginal value of the inputs into the security threat that $G$ destroys. This marginal cost of G's violence should equal the marginal value of the resulting reduction in the security threat, which is given by the left-hand side of Equation 25 (minus the marginal disutility of the background security threat). At the margin, the value of reducing the security threat $e$ should equal the cost of doing so in terms of destroying inputs into $e$. For example, labor that might have produced $Y^{n}$ could instead produce $X^{n}$, raising $N$ 's utility and thus prolonging the conflict. Another reason for the complexity of Equation 25 is that a reduction in $e$ does not always benefit $G$, since the reduction may also raise $N$ 's utility.

One connotation of the statics is that G's military measures are socially optimal only if the marginal disutility of the security threat is at least as great as the marginal utility of the destroyed inputs. In particular, unconditional surrender is socially optimal only if the harm done by a small security threat would exceed the value to $N$ of defense services.

\section{Intrastate Conflicts}

In some intrastate cases, one might measure the security threat $e$ by the probability that civil war will spill over the borders of the sanctioned area-a perennial problem in Africa. In any case, the most common sanction in intrastate conflicts is an arms embargo-especially a restriction on arms sold to the rebel group. Are such embargos efficient?

Denote as $X$ the rebel group's governance services, whether the populace wants them or not. $X$ is a direct function of the rebel group's arms $Y$, which it buys from the area $G$. $G$ may be in the same nation as rebel group $N$, or it may be elsewhere. By selling arms, $G$ finances the consumer good $M$. But the arms sales may also increase the security threat $e$ that afflicts $G$. $G$ 's arms embargo is represented by its restriction on exports to $N$, denoted as $\alpha_{i}(e)$. As $e$ increases, the restriction becomes more severe. $G$ produces $Y$ with labor $L_{Y}{ }^{g}$ and capital $K_{Y}{ }^{g}$. An example of such an embargo may be the United States restriction on arms sales to the Dominican Republic under Rafael Trujillo in 1958 (Kirshner, 1997).

$G$ seeks to maximize the utility of its representative resident. Formally, it wishes to maximize

$$
\begin{aligned}
& L=U^{g}\left[M^{g}, y, e\right]+\lambda\left[M^{g}\left(L_{M}^{g}, K_{M}^{g}\right)-P_{Y}\left(1-\alpha_{i}[e]\right) Y^{T}\right]+\alpha\left[E_{0}+E^{n}\left(\left[1-\alpha_{i}(e)\right] Y^{T}\right)-e\right]+ \\
& \beta\left[Y\left(L_{Y}^{g}, K_{Y}^{g}\right)-\left(1-\alpha_{i}[e]\right) Y^{T}-y\right]+\gamma\left[L_{0}^{g}-L_{M}^{g}-L_{Y}^{g}\right]+\eta\left[K_{0}^{g}-K_{M}^{g}-K_{Y}^{g}\right]+\mu\left[U^{n}(X[(1-\right. \\
& \left.\left.\left.\left.\alpha_{i}[e]\right) Y^{T}\right]\right)-U_{0}^{n}\right]
\end{aligned}
$$

The choice variables are $M^{g}, y, e, Y^{T}, L_{Y}{ }^{g}, K_{Y}{ }^{g}, L_{M}{ }^{g}$ and $K_{M}{ }^{g}$. Manipulating the first-order conditions leads to

$$
\frac{d U^{g}}{d e}=\propto
$$

That is, $G$ will choose the amount of security threat, and consequently the degree of the arms embargo, so that the marginal disutility to it of $e$ equals the marginal disutility of the background threat $E_{0}$-which in turn represents the minimal disutility of a security threat since $G$ cannot affect the background threat. Reducing $e$ to this level implies the loss to $G$ of some M due to the embargo's reduction of revenues. 


\section{DISCUSSION}

If nothing else, the Pigouvian tax provides the international policymaker with another tool in her kit. For example, it may be an apt penalty for nations that shirk their obligations to enforce economic sanctions against a rogue nation. One advantage of the tax over the sanction is that it may affect the political leader's spending power more rapidly and thus compel him to come to terms more quickly. Charron (2011) notes that an arms embargo is usually a reaction to military conflict rather than a preventive step. The tax may be the ounce of prevention desired.

Compared to traditional sanctions, the tax may better suit violations of such measures as the Security Council's freeze of financial accounts of the Bosnian Serb military or of the Haitian government; the Council's ban on commercial ships entering ports of the Bosnian Serb forces; or the ban on exports of diamonds from Angola that were not approved by the government-all measures that occurred in the mid-Nineties. One reason for imposing a tax rather than a sanction is that small financial assets may contribute little to the offender's depredations and may be hard to monitor; they may also serve a useful purpose. The Council may find it worthwhile to tax the use of small assets rather than try quixotically to ban the use of all assets, small or large. For example, in 1996, the Council's International Commission of Inquiry on Rwanda acknowledged that the bordering nations could not afford checkpoints to fully enforce the arms embargo (Charron, 2011). In Liberia in 2009, the United Nations Panel of Experts concluded that financial sanctions hadn't worked (Charron, 2011).

The tax is less coercive than the sanction since the aggressor can choose whether to pay. An aggressive leader may fight the sanction to show his constituents that he is not a tool of the superpower. The tax is less likely to trigger such defiance.

But a tax may be too modest a penalty for such international offenses as the Russian seizure of the Crimean peninsula in 2014, the German invasion of Poland in 1939, the Italian invasion of Ethiopia in 1935 (which League sanctions failed to stop, as Charron (2011) notes), the 1994 genocide in Rwanda, or the kidnapping of children to serve as soldiers for groups in the Democratic Republic of Congo in the early 2000s. In such cases, the efficient tax may approach infinity. The tax may be more suitable for less fateful incidents such as the theft of assets from Kuwait during its invasion by Iraq in 1990, or violations of the Security Council ban in 1993 on flights over Bosnia and Herzegovina. It may also apply to preliminary steps taken by rogue nations, such as the arrangements with Bosnian Serbs that enabled Serbia and Montenegro to attack Bosnia and Herzegovina (Charron, 2011). Similarly, those imposing sanctions could offer subsidies to extend a ceasefire between hostile nations, or levy a tax for each person displaced by a military conflict. Finally, the tax may penalize nations that violate an embargo by selling arms to such targeted nations as Eritrea in 2009 or Liberia in 1992.

One problem with either sanctions or taxes is that sometimes the security threat may arise from the actions of both the sender and the target. In the dispute over North Korea's nuclear arsenal, military tests and exercises by either the DPRK or by nations hostile to it may increase the security threat when it is a pure public bad.

This paper has treated sanctions as an exercise in static optimization. Another approach is to view the sanctioning and target countries as players in a game. Lacy and Niou (2004) find that given complete information, the sanctioner need not actually impose sanctions; a credible threat of imposing them could induce concessions, if the target is willing to concede. Hufbauer, Schott, Elliott, \& Oegg (2009) report only 11 threats in their 174 case studies of sanctions.

When should we model sanctions as a game, and when as a static exercise? The answer may sometimes depend on the relative economic power of the two countries. If the sanctioner is much more powerful than the target country, then the target may have to take the sanctioner's behavior as given. In that case, a static model may be more appropriate than a game. According to Hufbauer, Schott, Elliott, \& Oegg (2009, p. 105), "The median sender-to-target GNP ratio was 45 before 1985 and was 453 in the last 15 years of the $20^{\text {th }}$ century." On the other hand, two parties unequal in size may still play a diplomatic game when the smaller party can impose outsized costs on the larger party-consider North Korea and the United States. 


\section{REFERENCES}

Allen, S. H., \& Lektzian, D. J. (2012). Economic sanctions: a blunt instrument? Journal of Peace Research, 50, 121-135. doi: 10.1177/0022343312456224

Charron, A. (2011). UN sanctions and conflict: responding to peace and security threats. London: Routledge.

Hoffman, F. (1967). The functions of economic sanctions: a comparative analysis. Journal of Peace Research, 4, 140-159. doi:10.1177/002234336700400204

Hufbauer, G. C., Schott, J. J., Elliott, K. A., \& Oegg, B. (2009). Economic sanctions reconsidered. Washington, D.C.: Peter G. Peterson Institute for International Economics.

Kirshner, J. (1997). The microfoundations of economic sanctions. Security Studies, 6, 32-64. doi:10.1080/09636419708429314

Kohn, R. E. (2002). A Heckscher-Ohlin-Samuelson interpretation of the labor-environmental coalition in Seattle. Atlantic Economic Journal, 30, 26-33.

Krugman, P. R., Obstfeld, M., \& Melitz, M.J. (2012). International economics: theory and policy. Boston: Addison-Wesley.

Samuelson, P. (1949). International factor price equalisation once again. Economic Journal, 59, 181-196.

Samuelson, P. (1948). International trade and the equalisation of factor prices. Economic Journal, 58, 63184. 


\section{APPENDIX}

TABLE 4

DATASET

\begin{tabular}{rrrrrr}
\hline & & & & & GDPlevel \\
year & tests & ME/GDP & nuctests & GDPgrowth & $(1989=100)$ \\
\hline 1990 & 2 & 0.200 & 0 & -4.3 & 95.7 \\
1991 & 2 & 0.200 & 0 & -4.4 & 91.4892 \\
1992 & 1 & 0.250 & 0 & -7.1 & 84.99347 \\
1993 & 4 & 0.255 & 0 & -4.5 & 81.16876 \\
1994 & 1 & 0.263 & 0 & -2.1 & 79.46422 \\
1995 & 0 & 0.293 & 0 & -4.4 & 75.96779 \\
1996 & 0 & 0.290 & 0 & -3.4 & 73.38489 \\
1997 & 0 & 0.294 & 0 & -6.5 & 68.61487 \\
1998 & 1 & 0.349 & 0 & -0.9 & 67.99733 \\
1999 & 0 & 0.290 & 0 & 6.1 & 72.14517 \\
2000 & 0 & 0.291 & 0 & 0.4 & 72.43375 \\
2001 & 0 & 0.311 & 0 & 3.8 & 75.18624 \\
2002 & 0 & 0.300 & 0 & 1.2 & 76.08847 \\
2003 & 3 & 0.304 & 0 & 1.8 & 77.45806 \\
2004 & 1 & 0.294 & 0 & 2.1 & 79.08468 \\
2005 & 2 & 0.238 & 0 & 3.8 & 82.0899 \\
2006 & 10 & 0.240 & 1 & -1.0 & 81.269 \\
2007 & 7 & 0.244 & 0 & -1.2 & 80.29377 \\
2008 & 6 & 0.242 & 0 & 3.1 & 82.78288 \\
2009 & 16 & 0.219 & 1 & -0.9 & 82.03783 \\
2010 & 0 & 0.220 & 0 & -0.5 & 81.62765 \\
2011 & 0 & 0.221 & 0 & 0.8 & 82.28067 \\
2012 & 6 & 0.220 & 0 & 1.3 & 83.35031 \\
2013 & 9 & 0.239 & 1 & 1.1 & 84.26717 \\
2014 & 18 & 0.240 & 0 & 1.0 & 85.10984 \\
2015 & 18 & 0.242 & 0 & -1.1 & 84.17363 \\
\hline
\end{tabular}

tests $=$ number of missile or nuclear tests

$\mathrm{ME} / \mathrm{GDP}=$ military share of gdp

nuctests $=$ number of nuclear tests

GDPgrowth $=$ growth rate of real GDP

GDPlevel = level of GDP, with 1989 GDP equal to 100

Source of data on the military share of GDP: Bureau of Arms Control, Verification and Compliance of the US Department of State. Retrieved from https://www.state.gov/

Source of test data: Center for Strategic and International Studies, Missile Defense Project. Retrieved from https://missilethreat.csis.org

Source of data on growth rates of real GDP: The Bank of Korea 